\title{
ENVIGPGIKA
}

Envigogika: Charles University E-journal for Environmental Education ISSN 1802-3061

\section{ENVIRONMENTAL ECONOMICS AND POLICY: COURSE EVALUATION SURVEY}

\author{
Petr Šauer, Martin Zahradník \\ Envigogika 2013/VIII/2- Recenzované články/ Reviewed Papers \\ Publikováno/Published 06 09. 2013
}

DOI: http://dx.doi.org/10.14712/18023061.380

\begin{abstract}
The main objective of this paper is to outline the educational aspects of environmental economics referring to an example of a course taught at The University of Economics, Prague.

A quantitative survey among students was conducted to describe their perceptions of the environmental topics and the diverse components of the course. This learners' perspective was compared with students' examination results and their level of activity in seminars. One of the main questions asked in this text is: did students interested in economic policy and regional economics consider the environmental orientation of the course important? And if yes, what aspects of the course did they value, what benefits did they get from the course, how did they manage the information resources and what role did this play with regards to students' concern for environmental issues?

Probably the most important finding of the research was the students' advocacy of environmental economics as a beneficial part of curriculum both by those clustered as 'environmentalists' and 'non-environmentalists' (or even 'anti-environmentalists'). Students appreciated having the chance to participate actively in the course. A wellbalanced proportion of lectures and seminars with enough space for deep discussion seemed to be crucial for retaining students' interest. The data didn't equip us with sufficient information to construct regression models with reasonable predictive power concerning exam results. A challenge for further research is to work with a better informed analysis of students' learning strategies.
\end{abstract}

This type of quantitative research dealing with students of environmental economics and policy has not been conducted at a national level yet.

\section{Key Words}

Environmental economics, environmental policy, environmental management, teaching, learning, pedagogical evaluation 


\section{Introduction}

Environmental degradation and protection are considered to be important global, regional and local challenges in most parts of the world. Solutions to environmental problems require addressing various social, technological, economic, legal and political problems, while the ability to solve environmental problems requires education, including education at university level (Lozano 2006; Wright 2007)

The paper presents selected results from a Czech research project investigating the role of newly applied methods of teaching-learning of several environmental courses at university level. One of the tasks of the project is to investigate the 'Environmental Economics and Policy' course taught at the Department of Environmental Economics at the University of Economics, Prague.

This follows a project conducted in 2006, in which various employers from public administration institutions, large and medium enterprises and non-profit organizations were surveyed as to their expectations of graduates from environmental economics, policy and management. According to their opinions, graduates should have a strong theoretical knowledge as a basis for resolving practical problems. They should already be familiar with the problems of 'practical life', and ideally already have some experience with work placement during their studies. A good knowledge of environmental protection law and also of the English language was noted as very important. Respondents in the survey also stressed the importance of the knowledge of ecology issues. No requirement of knowledge about environmental technologies appeared in the employers' responses (Sauer 2007: 4350).

The research project described in this article investigated the students' reflections on the course. The paper aims to provide answers to the following questions: was the course perceived to be important for the students? What did they learn in the course, and what were their learning strategies? We have also tried to explain the results of the examinations - in general terms - and the various components reflecting various students' competences.

\section{Information about the Course}

The course 'Environmental Economics and Policy' aimed to introduce students to the principal theoretical findings in environmental economics, policy and management and their practical applications. The course was classified as obligatory for students of the follow-up Master's specialisations 'Economic Policy' and 'Regional Studies', and as a noncompulsory option for other interested students. The course was designed as a nonspecialist course. Similarly to Stubbs and Coclin's (2008) design, the course helped students to understand the topic from different perspectives, i.e. not only from a single economic paradigm such as neoclassical etc. It also dealt with human values and their importance for individual behaviour in economic and political systems; as Arbuthnott (2009) has noted "...if attitude change is to translate into altered behaviour, education must extend beyond attitudes to assist people to act in ways consistent with their values..."

Upon successful completion of this course, students should have a thorough understanding of the relevant theories, concepts and methodology of the subject. The new teaching methods mentioned above included numerous games, small-scale economic 
laboratory experiments, numerical illustrations, brainstorming, and standard class discussion. Furthermore students made presentations on topics derived from media sources related to the course content in each seminar. The course consisted of regular lectures followed by seminars where the total number of 102 participants in the autumn run and 81 participants in spring run of the course was divided into smaller groups of approximately 20 students, enabling their active involvement. The overall workload of the course represented 6 ECTS credits (approx. 160 hours).

A brief summary of the course content is as follows:

- environment, finite nature of its components and factors as the object and subject of cognition, evaluation and decision-making of various (human) subjects; including a short explanation of key ecological principles and laws;

- people's values, needs and (economic) preferences, their relevance to environmental policy;

- analytical and multi-criteria assessment of environmental quality;

- economic context of the negative implications of environmental degradation (economic damage resulting from environmental degradation, methods and importance of their quantification);

- assessment of environmental impacts of investment; costs of and expenditures on environmental protection and their quantification, approaches to evaluation of their effectiveness;

- the concept, principles and main tools of environmental policy;

- the principle and application methods of selling pollution rights as an instrument of environmental policy; negotiations and compensation between polluters and sufferers as a way of solving environmental problems; the negotiation model between state authority and polluters under asymmetric economic information and application of economic instruments;

- optimum environmental quality and impacts of environment-oriented technological development; and the macroeconomic context of environmental policy.

A textbook was designed for the method of teaching described above. The students also used a collection of landmark, original (mostly theoretical) papers covering all important parts of the course. The students were encouraged to follow the media in order to find suitable topics for their presentations and also to use specialized sources of literature for preparing their presentations, including on-line sources.

\section{Survey Method}

\section{Respondents}

The survey was conducted specifically among students of the one-semester 'Environmental Economics and Policy' course attending the above mentioned specializations of 'Economic Policy' and 'Regional Studies' at the University of Economics, Prague. The number of students in the course was 183 (autumn 2008: 102 students; spring 2009: 81 students). 
As one teacher taught the course in both semesters and used the same teaching methods, tools and methods of examining the students, questionnaires from both semesters are entered in one data set.

\section{Data Collection}

The data were collected through semi-anonymous questionnaires after the final tests in the autumn and the spring semesters of the academic year 2008 - 2009. There was no connection between students' names and the data, but we were able to connect data from the survey with the exam results of specific students.

The response rate was over 93 percent so the survey was completely representative and we consider the results valid with no need to conduct deep statistical testing of its significance when referring to the last two semesters (the number of the questionnaires returned was 171 from 183 (autumn 2008: 96; spring 2009: 75). If we assume more general conclusions about the student population at the Faculty of Economics and Public Administration, requisite tests of statistical significance are employed. The numbers of valid responses, i.e. number of questions that were answered, are shown later in the paper as appropriate.

\section{Questionnaire Structure}

The questionnaire consisted of several batteries of questions with specific areas of interest:

- Competences gained through participation on the course as perceived by students

- Students' evaluation of competencies and benefits gained in the course

- Information management (students' choice of learning resources)

- Students' value orientations and attitudes towards environmental issues

- General comments and attitudes to the course and the teacher

- Personal characteristics (specialisation, whether obliged or opting to take the course, etc.)

The questionnaire responses were organized mainly in 5 point scales of agreement with specific statements, or 6 point scales evaluating importance of different parts of the course and learning resources. Within the questionnaire, the New Environmental Paradigm Scale was used to assess environmental concern (Dunlap et al. 2000: 427), and students were also asked to rank a set of 25 general values. The questionnaire comprised opened questions eliciting comments on strong and weak parts of the course and for specification of on-line resources used by the students.

We analysed students' results in the course together with their responses to the questionnaire. The students' assessment consisted of several parts: their activity in the seminar, the quality of the oral presentation of their projects, their presence at lectures and seminars, and the final test (a set of open questions). An additional part included a voluntary interview with the teacher for those who wanted to discuss and improve their results. 
Therefore, when we speak about applications in the context of this survey we mean the introduction of practical examples in the learning process. Students were for example asked to choose a topic for their presentation in public media and apply the theories learned to find possible solutions. Further, the final test consisted of two parts. The first part was to assess theoretical knowledge, and the second part the application of this theory in solving practical examples.

When we consider activity, active participation and communication, we refer to students' presentations and open discussion during seminars.

\section{Results}

\section{Importance of the Course for the Students}

The students of Faculty of Economics and Public Administration were preparing themselves for taking important roles in public policy decision-making processes at national and regional levels. Therefore we could consider the students' orientation in the subject matter as an important factor for the successful resolution of environmental problems in the future.

But did the students themselves also consider environmental issues as important? The prevailing neo-conservative climate of the Faculty tends to disparage the importance and validity of environmental studies. Did the students in such an environment find the orientation of the course beneficial, or did they perceive it more as an unnecessary, timewasting activity?

The data provided us with a clear answer to this question. The majority of students $(80 \%)$ agreed with the statement "I find the course orientation to environmental issues beneficial" while only $5 \%$ expressed their disagreement (see Figure 1).

\section{Figure-1: Importance of the Course to the Students}

\section{I find the course orientation on environmental issues beneficial.}

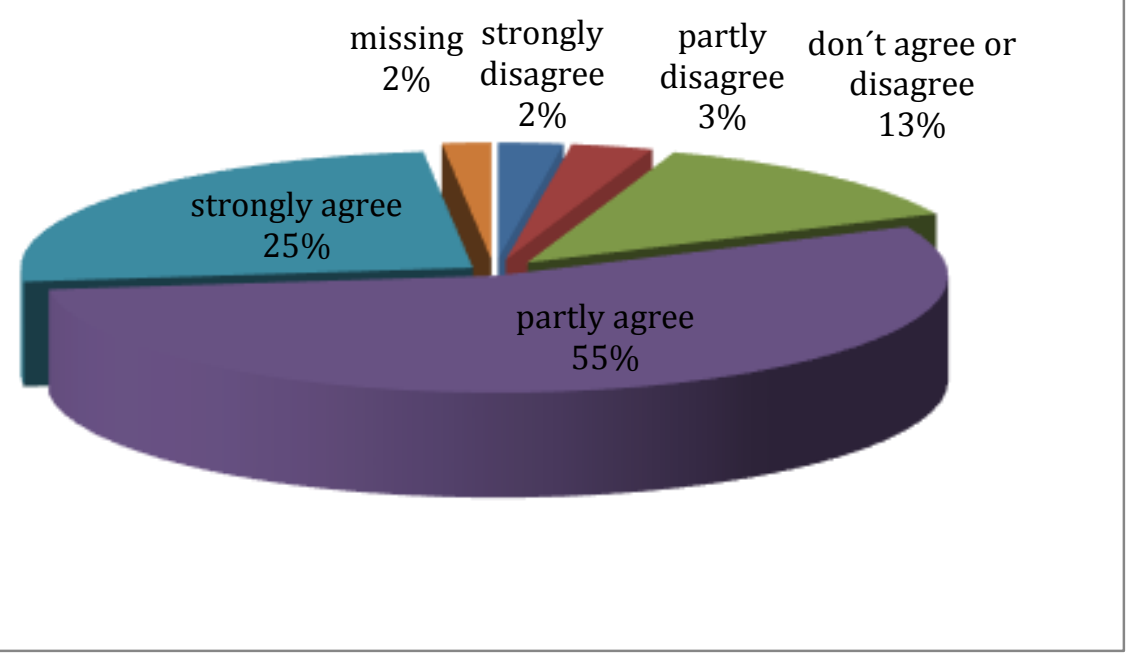

3 missing cases, 168 of 171 valid, 5 point scale 
Students were asked to explain their level of agreement in open comments. Responses were coded by key reasons for their evaluation of the course and then structured into categories which were identified from the answer 'clusters' in the data. The approach applied principles of Grounded Theory analysis (developed by Glaser and Strauss: 2009). It was interesting to note the reasons why the students found the course orientation beneficial: most of the students who provided comments deemed the topic an important issue in itself, considered environmental problems important and welcomed knowledge and skills that could lead to their resolution ${ }^{1}$.

Other students deemed the topic important because it was a widely discussed social problem. These students often stressed the role of media in promoting environmental issues. Students therefore wanted to have a good grasp of the topic. In other words they wanted to be aware of what is socially constructed (interpreted) as important in anticipation of their future professional roles. This was very clear in the comments of those students who regard the importance of environmental issues with scepticism: for example, they felt the need to be conversant in the topic because they feared manipulation by ecological pressure groups. Environmental degradation is widely discussed and so it is expected that a university-education person should be well-informed about environmental issues and able to differentiate between credible and false assertions.

While the specific reasons may differ, the environmental economics course was perceived by the students as a relevant part of the curriculum.

\section{The Course Benefits Perceived by the Students}

Knowledge application as a fundamental competence delivered by education is often emphasized especially in the context of education for sustainable development. The need for such competence is stressed by both future employers (Sauer 2007: 43-50) and pedagogical experts. Such considerations are the basis of the dynamic model for ESD competences (c.f. Sleurs 2008:26), further developed by UNECE (2008:17) into the table of specific competences as desired learning outcomes in the ESD area.

It is relevant to ask whether the students appreciated the emphasis put on the application of theoretical knowledge and open communication in current education or whether they felt it slowed down their learning process at the expense of time needed for gaining new knowledge.

The aim of this course was to find a balance between different educational aspects such as gaining new knowledge, its practical application, exposing students to different teaching approaches and encouraging discussion.

Students' comments on the course benefits and its strong and weak aspects predominantly advocated open communication (active participation in discussions following the theoretical lectures as well as students' presentations) with emphasis on application of gained knowledge. Providing opportunities for knowledge application and communication were stressed as important course benefits:

\footnotetext{
${ }^{1}$ A total of 150 of the 171 students provided comments. Of these, 69 mentioned the course topic as an important issue itself (14 of them also provided other reasons as appreciation of multiple perspectives in dealing with practical problems for ex.).
} 
[Before attending the course,] I had only superficial knowledge of most environmental issues. For me personally, it was very useful to have an opportunity to analyse actual issues in discussions, where it was possible to express one's views, as well as listen to the opinions of others.

This sentiment was repeated in open comments on the strengths of the course:

In the course, actual practical examples were used to demonstrate the themes; thus we were not only encountering learning of theories, but rather the practical part of the issues was shown.

I found the discussions during the seminars most beneficial; this is how all courses should be structured, at least in my opinion, i.e. in the form of open discussion.

What I appreciated most: possible practical use of discussed topics, discussions following presentations.

The quantitative scores validated students' perception of the important role of the application of theory to practical examples and open communication in the course. Students mostly agreed on the scale from 1 , strongly disagree to 5 , strongly agree with the following statements:

- Methods of applying acquired knowledge in problem solving were part of the course (mean 4).

- I used the knowledge acquired in the course while dealing with the issues discussed in class. (mean 3.8)

- Discussing the studied issues with fellow students was part of the course (mean 4.4).

However, students' responses are not only positive. While they welcomed the course structure, they also refer to the negative effect of too many students' presentations in any one seminar. In this case the responses refer to the loss of time which would preferably have been spent on deeper discussion. There is evidence that the students' presentations were also among the least appreciated parts of the course:

...too many students attending the seminars with discussions.

Classes where only presentations were given were very monotonous.

One negative thing I would point out was the large number of students in seminars which resulted in a limited time for discussion.

The problem mentioned here was caused by an unexpectedly high number of students who attended the autumn semester and a limited time combined with the necessity of maintaining equal opportunities for all to make their voice heard.

Looking at the weight which students put on specific parts of the course we can see very homogenous scores. Students were asked to assess on a 6 point scale $(0=$ no benefit 
at all; 5 = substantial benefit ${ }^{2}$ how important and benefitting they found the following course components:

Table 1: The Course Benefits Perceived by the Students

\begin{tabular}{|l|l|l|}
\hline Competence & Mean & Valid cases \\
\hline New knowledge during the & 3.10 & 171 \\
\hline $\begin{array}{l}\text { Communication-discussion } \\
\text { lessons }\end{array}$ & 3.08 & 171 \\
\hline Communication-presentation & 3.23 & 170 \\
\hline Competencies for solving of actual problems & 3.09 & 168 \\
\hline
\end{tabular}

6 point scale $0=$ no benefit at all; $5=$ substantial benefit

Despite the criticism of too many presentations in the seminars which was manifested in open comments, we found prevailing support for the active involvement of the students. Communication in the form of students' presentations gained the best score 3.23. The overall mean in all considered aspects of the course is slightly higher than 3 , i.e. "beneficial". Students were also asked to evaluate "work with IT" which was not the main subject of the course. The mean for this aspect was 1.85; with respect to the results discussed below, this fact assures us that the students' responses were valid. Such results lead us to the conclusion that generally speaking the goal of a well-balanced course was reached.

\section{Management of information resources}

We were further interested in ascertaining the diverse sources of information accessed by the students in their preparation for the final test and the interview to investigate the role of on-line resources. We assumed that students increasingly used online resources. For example, there was a shared on-line space with study materials and any information relevant to the exams established by the students themselves. Did these changing information management strategies influence the final results?

To answer these question we applied the same six point quantitative scale as was mentioned in the previous chapter to assess the benefits of specific information resources with additional specification of on-line resources ( $0=$ no benefit at all; $5=$ substantial benefit).

To prepare for the final examinations students clearly preferred the recommended literature (mean 4.37) and their notes from lessons and seminars (mean 3.99). The prevailing opinion concerning on-line resources were rather negative with a mean close to the statement "very little benefit" (1.23). Furthermore, the usage of on-line resources correlated negatively with the final examination results (Pearson coefficient $-0.229^{3}$ ). In

\footnotetext{
${ }^{2}$ Full scale: $0=$ no benefit at all; $1=$ very little benefit; 2 = a little beneficial; $3=$ beneficial; $4=$ very beneficial; 5 = substantial benefit)

${ }^{3}$ The ordinal scales were transformed into dichotomic variables when required by the analysis.
} 
other words: students who valued on-line resources as more beneficial usually received worse results in the final exam. A clue to this is provided by looking at the specification of the resources. Students used almost exclusively on-line resources provided for the lay public. Although they used web pages of several ministry offices, Google, Wikipedia or online dictionaries to clarify concepts and terminology, which can undoubtedly be helpful, no reviewed articles or scientific databases appeared in their list of on-line resources, even when they were recommended to do so.

But it is obviously not only the quality of the on-line resources relied upon by students which might have negatively impacted on their examination results. The type of student according to his/her information management strategy and other characteristics plays a more significant role. Better results were gained by students who put emphasis on using their own lecture notes (Pearson c. $+0,178$ ) and not surprisingly we have found the preference of notes correlated with students' presence at lectures and seminars (Pearson c. $+0,201)$. So we conclude that students who steadily attended the lectures and seminars and made notes were better prepared for the final examinations.

\section{Environmental Concern}

Besides the influence of information resources management on students' performance, we tried to describe the potential role of environmental concern. We applied the New Environmental Paradigm (NEP) scale developed by Dunlap and Van Liere, which "is treated as a measure of endorsement of a fundamental paradigm or worldview, as well as of environmental attitudes, beliefs, and even values" (Dunlap el al 2000: 427). The NEP scale consists of fifteen statements concerning attitudes towards the environment to which respondents express their level of agreement. While there are discussions about the possible internal dimensions of the NEP scale (balance of nature, limits to growth, and human domination of nature), we consider the scale along with Dunlap's original intention to be one-dimensional (Dunlap el al 2000: 434) and represented by the overall mean.

The data proved there was no significant correlation between the NEP score and students' performance. Nevertheless, the research results corresponded with global findings regarding the gender difference in environmental concern (Soukup 2001:7). Reflecting the trend in the wider population, female students of the Faculty of Economics and Public Administration expressed more pro-environmental attitudes then male students. Looking at attitudes, we also found that the students of Regional Studies were more aware of environmental issues than students of Economic Policy.

When considering environmental values and attitudes we should mention students' scaling of a set of 25 general values, including environmental values. The value set (originally developed by Czech teachers and sociologists in the 1980s) consisted of five groups of values (socially oriented, lifestyle, family life, career and the environment). Students clearly ranked family oriented values (happy family life, deep love with a partner) more highly, while social and environmental values appeared lower down the list. In the autumn run of the course, students ranked the values pre- and post-course to assess potential changes in value preferences, but not a single change occurred in the value order. On the one hand, this may be understood as failure in fulfilling one of the commonly defined goals of education for sustainable development: to promote values oriented toward change towards sustainability (Sterling in Dlouha 2009). On the other hand, it may be understood as a positive aspect: the neutrality of the teacher's presentation of different normative perspectives respected the attempt by academia to be value free. 


\section{Discussion: an Attempt to Explain the Exam Results}

Despite Dunlap's findings of a positive correlation between education and proenvironmental attitudes - "the better educated were assumed to be exposed to more information about environmental issues and to be more capable of comprehending the ecological perspective implicit in the NEP" (Dunlap el al 2000: 429) - there was no significant relationship between examination results and the NEP score in our findings. This was probably caused by the homogenous character of our group of respondents at the same educational level. Czech distinctions concerning environmental values and perception of them (the translation of the NEP questionnaire is not culture-specific) might have played a role (cf. Franěk, 2012).

But our expectation was a little different from Dunlap's explanation. We assumed that students with more pro-environmental attitudes would be better motivated and thus achieve better results. This hypothesis was contradicted by the data ${ }^{4}$.

Considering the findings on students' information management strategies and environmental concern we tried to construct a regression model which would allow us to predict exam results by involving environmental attitudes or any other relevant variables. Unfortunately our effort was unsuccessful. The predictive power was insignificant even when we tried to develop such models for specific exam results (such as application or theoretical parts of the test, activity in seminars, presentation, etc.).

Our research didn't provide sufficient data for the development of predictive models. There might be non-linear regressions which were not tested in our models, or the variables might not cover the considered phenomena fully. We also assumed that there might be other important influences which were not captured by the survey. One of the possible explanations might be found in the role of intelligence or cultural capital (Sullivan: 2001): there are smarter and less gifted students, and students with richer and poorer cultural backgrounds, and such differences might lead to distinct results. But the inclusion of IQ tests seems to be unrealistic. It would burden the respondents with too many questions and from a pedagogical perspective there are more interesting differences which can be influenced. Further research should deal with more thoroughly elaborated questioning of students' learning strategies (for example time spent preparing for the test or presentation). However, we can find several interesting correlations.

While searching for a way to characterise the students who were awarded highest scores for their active approach, we found those who chose the course optionally were more active than the obligatory participants and also that men were more active than women. In both cases there were no significant differences in overall examination results.

We used cluster analysis in another attempt to find interesting information about the groupings of types of students defined by their active approach to seminar discussions, results and opinions. Students' results in the application part of the test, their active participation in discussions, specialization, sex, and their attitudes towards the environment along with their general opinion of the course (in terms of whether it was beneficial or not) allow us to identify four different groups of students. Two of them were

4 All correlations and differences of means mentioned in this chapter were statistically tested to a $5 \%$ level of significance so we can refer to the total student population of the faculty. 
quite small but interesting because they consisted of students with markedly varying value orientations:

The most distinctive group we would call 'anti-environmentalists'. This group contained a minority of students, all of whom are men and almost all of whom are studying Economic Policy ${ }^{5}$. They tended to disagree with the NEP pro-environmental statements (general mean 2.15 is the lowest in all groups and corresponds with 'partly disagree') and they were also the most active students in the discussions ${ }^{6}$.

Another distinctive but small group of only 6 students is characterized by the best results in the application part of the final test, highest level of pro-environmental attitudes (general mean 4.35) and strong agreement with the statement 'I find the course orientation on environmental issues beneficial' (mean 4.83). Therefore we would call them 'environmentalists'.

The remaining two groups are much larger: The 'Women's' group, because of the 62 members of this group $95 \%$ were women and, compared to the Economic Policy group, its scores were higher in environmental concern (general mean 3.71) but had slightly worse results in the application part of final test (mean 14.50). But this difference can be interpreted only for students in the last two semesters. We are missing sufficient statistical significance for generalisation to a wider population of students.

The last group of 78 members with a prevailing specialization in Economic Policy $(82 \%)$ represents the residuum of students who have no specific attitudes towards the environment (mean $3.04=$ 'don't agree' or 'disagree') and average scores in other considered variables.

In our opinion it is difficult to compare these clusters with other surveys (Zsóka et al. 2012; Segalàs et al: 2012) due to the different set of variables used for defining the groups of respondents. Attitudes towards the environment represented by the NEP scale played a dominant role in our case (we were led by our interest in influencing the prevailing neo-conservative climate of the Faculty on students perceptions of environmental economics) while other studies which used multiple scaling methods in ESD courses considered different dimensions as an important part of their analysis and explored the clusters from the perspective of e.g. consumer behavior (Zsóka et al. 2012).

\section{Conclusions}

Probably the most important finding of the research is the students' advocacy of environmental economics as a beneficial part of the curriculum. The need to get a firm grasp of environmental issues is stressed by both environmentalists and those who may not be as enthusiastic in studying environmental issues but are aware of the emphasis placed on environmental problems by media and society.

Students appreciated their active participation in the course. They stressed examples of practical applications of the knowledge gained and open discussions as most beneficial and positive aspects of the learning process. But they also express dissatisfaction with the seminar structure which currently includes too many presentations

\footnotetext{
5 The group consists of 14 students and only 2 of them are "regionalists". 159 valid cases were considered in cluster analysis.

${ }^{6}$ The significant roles of variables were tested by One Way Anova.
} 
leading to monotonous seminar format and not making space for substantial discussions. A well balanced proportion of lectures and seminars with enough space for a deep discussion seem to be crucial for keeping the students engaged.

The interest which can fortify students' attendance during the course and encourage them to write notes as a valuable source of information for final examinations is important for good examination results. Regarding information resources, we recommend focusing on ways to encourage the students to be more discerning in their choice of resources, in particular good quality reviewed texts in on-line scientific journals and databases to avoid them relying on web sites targeting the lay public.

We would like to stress here that he data doesn't equip us with sufficient information to construct regression models with reasonable predictive power concerning exam results. A challenge for further research is to work with a better informed analysis of students' learning strategies.

Our findings about the role of pro-environmental attitudes revealed that there were no fewer motivated and less active students in the course with anti-environmental attitudes which had worse results than we might expect. The less environmentally-oriented the students were, the more actively they engaged in discussions'. The cluster analysis exposed two "extreme" groups of students and both 'environmentalists' and 'antienvironmentalists' achieved similar results in the application part of the final test and in overall exam results. The anti-environmentalists, moreover, proved their active participation in seminar discussions by scoring significantly more in this area $^{8}$. And despite the different evaluation scores of the course on environmental economics ${ }^{9}$ both groups prevailingly agreed on its beneficial nature.

It is also important to note that the results of our survey were further utilized in the process leading to the establishment of a wholly new course on environmental economics and policy in another faculty of the University of Economics, Prague. The new course, the first of its kind, at the Faculty of International Relations, took inspiration from the results of the described research project, focussing even more on knowledge application and open communication in the learning process.

\section{Acknowledgements}

Research was undertaken under the project Innovation of Educational Modules, Development of Computer Supported Learning (e-learning) and Introduction of Evaluation Mechanisms for Life-long Environmental Education (E-V-Learn), funded by Ministry of Environment CR, VaV SP-4h6-142-08, and the PRVOUK, research program of the Charles University in Prague.

\footnotetext{
7 Pearson coefficient $-0,274$ is significant on $1 \%$ level.

${ }^{8}$ Anti-environmentalists average score in activity points was 6,86 while environmentalists gain an average points 4,67 . The difference is significant on $a=0,05$.

${ }^{9}$ Anti-environmentalists average level of agreement with statement I find the course orientation on environmental issues beneficial was 3,57 with median 4 (partly agree) and the environmentalist mean was 4,83 with median 5 (strongly agree). The difference is significant on $a=0,01$ Not sure about these explanations below text - other manuscripts do not use them, probably should be integrated in the text( ?)
} 


\section{References}

- Arbuthnott, K. D. (2009). Education for sustainable development beyond attitude change. International Journal of Sustainability in Higher Education, 10(2), 152163. Retrieved from http://www.emeraldinsight.com/10.1108/14676370910945954 http://dx.doi.org/10.1108/14676370910945954

- Dlouhá, J. (2009). Competences in environmental education. Envigogika, 4(1), Retrieved from http://www.envigogika.cuni.cz/index.php/Envigogika/article/view/34

- Dunlap, R. E., Van_Liere, K. D., Mertig, A. G., \& Jones, R. E. (2000). Measuring Endorsement of the New Ecological Paradigm: A Revised NEP Scale. Journal of Social Issues, 56(3), 425-442. Retrieved from http://doi.wiley.com/10.1111/00224537.00176 http://dx.doi.org/10.1111/0022-4537.00176

- Franěk, M. (2012). Nature Relatedness Scale. Envigogika, 7(1), Retrieved from http://www.envigogika.cuni.cz/index.php/Envigogika/article/view/69 http://dx.doi.org/10.14712/18023061.69

- Glaser, B. G., \& Strauss, A. L. (2009). The Discovery of Grounded Theory: Strategies for Qualitative Research. : Transaction Publishers.

- Lozano, R. (2006). Incorporation and institutionalisation of SD into universities: breaking through barriers to change". Journal of Cleaner Production, 14(9-11), 787-796. Retrieved from http://linkinghub.elsevier.com/retrieve/pii/S0959652606000175 http://dx.doi.org/10.1016/i.jclepro.2005.12.010

- Sauer, P. (2007). How to teach applied environmental economics. International Journal of Business, Management and Economics, 3(9), 43-50.

- Sleurs, W., \& al., (2008). Competencies for ESD (Education for Sustainable Development) teachers: A framework to integrate ESD in the curriculum of teacher training institute", Comenius 2.1 project 118277-CP-1-2004-BE-Comenius-C2.1. Brussels: UN ECE. Retrieved from http://www.unece.org/env/esd/inf.meeting.docs/EGonInd/8mtg/CSCT\%20Handbo ok Extract.pdf

- Soukup, P. (2001). ISSP - The Environment. Praha: Sociologický ústav AV ČR.

- Stubbs, W., \& Cocklin, C. (2008). Teaching sustainability to business students: shifting mindsets. International Journal of Sustainability in Higher Education, 9(3), 206-221. Retrieved from http://www.emeraldinsight.com/10.1108/14676370810885844 http://dx.doi.org/10.1108/14676370810885844

- Wright, T. S. A. (2007). Developing research priorities with a cohort of higher education for sustainability experts. International Journal of Sustainability in Higher Education, 8(1), 34-43. Retrieved from http://www.emeraldinsight.com/10.1108/14676370710717571 http://dx.doi.org/10.1108/14676370710717571 
- Unece, (2008). Report of The UNECE Steering Committe on Education for Sustainable Development in its third meeting. : UN ECE, Steering Committee on Education for Sustainable Development.. Retrieved from http://www.unece.org/fileadmin/DAM/env/esd/inf.meeting.docs/SC/SC3/ece.cep.ac.13.2008.2.add.1.e.AC.pdf

- Zsóka, Á, , Szerényi, Z. M., Széchy, A., \& Kocsis, T. (2013). Greening due to environmental education? Environmental knowledge, attitudes, consumer behavior and everyday pro-environmental activities of Hungarian high school and university students. Journal of Cleaner Production, 48, 126-138. Retrieved from http://linkinghub.elsevier.com/retrieve/pii/S0959652612006233 http://dx.doi.org/10.1016/j.jclepro.2012.11.030

- Sauer, P., Mensik, S., \& Andrews, R. (1994). Social values and the environment. Acta Oeconomica Pragcusia, 3(4), 21-23. 